Bangladesh J. Plant Taxon. 18(2): 93-104, 2011 (December)

(C) 2011 Bangladesh Association of Plant Taxonomists

\title{
GENETIC VARIATION AMONG IRANIAN ALFALFA (MEDICAGO SATIVA L.) POPULATIONS BASED ON RAPD MARKERS
}

\author{
Fatemeh Mohammadzadeh ${ }^{*}$, Hassan Monirifar ${ }^{1}$, Jalal Saba, Mostafa Valizadeh ${ }^{2}$, \\ Ahmad Razban Haghighi ${ }^{1}$, Bahram Maleki Zanjani, \\ MARYAM BARGHI ${ }^{1}$ AND VAHIDEH TARHRIZ ${ }^{3}$ \\ Faculty of Agriculture, Zanjan University, Zanjan, Iran
}

Keywords: Alfalfa; RAPD; Genetic diversity; Analysis of Molecular Variance; Cluster analysis.

\begin{abstract}
Genetic diversity among and within 10 populations of Iranian alfalfa, from different areas of Azarbaijan, Iran was analyzed by screening DNA from seeds of individual plants and bulk samples. In individual study, 10 randomly amplified polymorphic DNA (RAPD) primers produced 156 polymorphic bands and a high level of genetic diversity was observed within populations. The averages of total and within population genetic diversity were 0.2349 and 0.1892 , respectively. Results of analysis of molecular variance (AMOVA) showed the great genetic variation existed within populations (81.37\%). These Results were in agreement with allogamous and polyploid nature of alfalfa. Cluster analysis was performed based on Nei's genetic distances resulting in grouping into 3 clusters which could separate breeding population from other populations. Results of cluster analysis were in consistent with morphological and geographical patterns of populations. The results of bulk method were different from individual analysis. Our results showed that RAPD analysis is a suitable method to study genetic diversity and relationships among alfalfa populations.
\end{abstract}

\section{Introduction}

Alfalfa (Medicago sativa L.) is the most important forage legume (Veronesi et al., 2010), originated in Caucasus, northeastern Turkey, northwestern Iran and Turkmenistan (DehghanShoar et al., 1997), though Iran is known as central origin (Hanson, 1988). It is an autotetraploid and allogamous plant (Flajoulot et al., 2005). These features lead to its high genetic complexity (Gherardi et al., 1998; Flajoulot et al., 2005). Therefore, a high degree of genetic diversity can be found within and between populations (Mengoni et al., 2000). These factors cause the complication of breeding improvement in alfalfa (Gherardi et al., 1998). However, since alfalfa is an agronomically important crop, its improvement is necessary, especially to increase pest or disease resistance, forage quality and forage yield (Volence et al., 2002). Alfalfa cultivars are synthetic varieties developed by intercrossing the selected parents and advancing their offspring through three or four generations of seed increase (Rowe and Hill, 1999). So, genetic studies such as differentiation between cultivars and estimating the genetic diversity within and between populations are important in alfalfa breeding programs to use some of these populations as selected parents and producing higher yielding cultivars (Veronesi et al., 2010).

*Corresponding author: E-mail: fidafeh_m@yahoo.com

${ }^{1}$ Agricultural Biotechnology Research, Institute of Iran (ABRII) for Northwest and West of Iran, Tabriz, Iran.

${ }^{2}$ Faculty of Agriculture, Tabriz University, Tabriz, Iran.

${ }^{3}$ Sari Agricultural Sciences and Natural Resources University, Sari, Iran. 


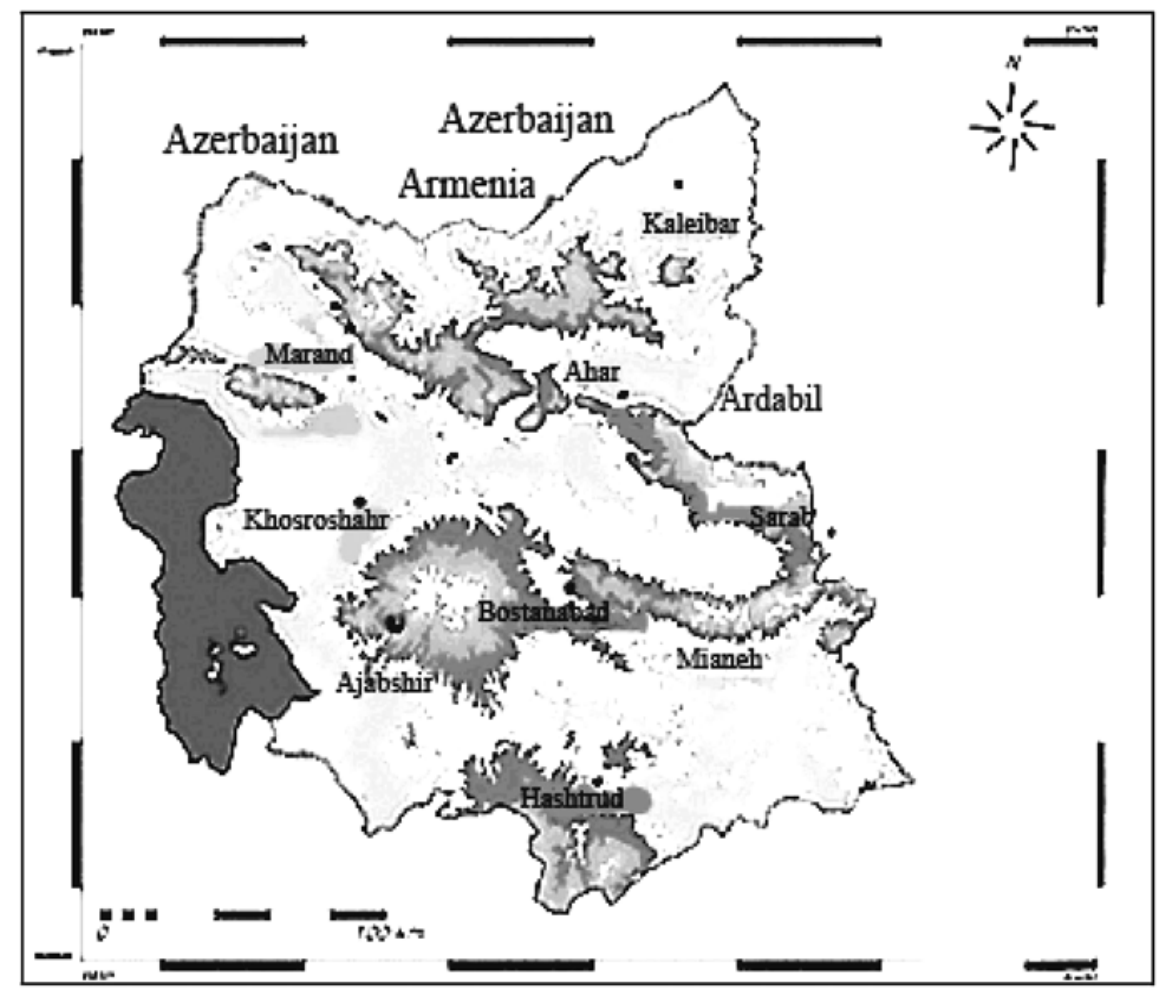

Fig. 1. Locations of alfalfa populations (Azarbaijan, Iran). Source: http://www.ncc.org.ir

DNA-based molecular markers such as RFLPs, SSRs and RAPDs are extensively used to estimate genetic diversity and establish the relationships between plant cultivars (Kidwell et al., 1994; Mengoni et al., 2000). These markers have more polymorphism loci than other methods such as isozyme analysis (Jenczewski et al., 1999) and since they are not affected by environment conditions and plant development level, they can estimate genetic diversity in populations more precisely (Tucak et al., 2008).

In RAPD-PCR technique, genomic DNA is amplified with arbitrary 10-mer oligonucleotide primers to produce DNA fragment polymorphisms (Gherardi et al., 1998). RAPD markers are independent of DNA quantity (Jenczewski et al., 1999) and they do not require previous knowledge of genome (Rahman, 2006; Tucak et al., 2008). Therefore, RAPD analysis is considered as rapid, simple and inexpensive method (Williams et al., 1990; Rahman, 2006) to study genetic structures such as genome mapping, estimating of genetic diversity within and among populations and discriminating among plant populations and cultivars such as alfalfa (Arzani and Samei, 2004; Vandemark et al., 2006; Rahman, 2010).

Although RAPD procedure is a useful method, its application might be limited when a large number of individuals are studied (Yu and Pauls, 1993). This problem could be solved using bulked DNA samples as DNA templates in RAPD amplifications (Michelmore et al., 1991). In 
this study we aimed to estimate genetic diversity within and among alfalfa populations of Azarbaijan (Iran) by RAPD markers. We also grouped these populations with analysis of individual samples and bulked DNA samples.

\section{Materials and Methods}

Plant materials: Nine tetraploid Iranian alfalfa native ecotypes collected from different areas of Azarbaijan, Iran (Fig. 1) and one breeding population (Ghareh Yonjeh) were employed in this study (Table 1). In each population, 30 seeds were randomly selected for individual plant analysis. A mixture of 30 randomly selected seeds per population was also used to prepare bulked DNA sample.

Table 1. List of alfalfa populations used in the present study.

\begin{tabular}{lllcl}
\hline $\begin{array}{l}\text { Population } \\
\text { number }\end{array}$ & $\begin{array}{l}\text { Population } \\
\text { name }\end{array}$ & $\begin{array}{l}\text { Collection } \\
\text { site }\end{array}$ & $\begin{array}{c}\text { Elevation } \\
(\mathrm{km})\end{array}$ & \multicolumn{1}{c}{ Planting type } \\
\hline 1 & Gran chay & Kaleibar & 750 & Irrigated farming, native ecotype \\
2 & Zonorag & Marand & 1850 & Dry farming, native ecotype \\
3 & Sivan & Marand & 2000 & Irrigated farming, native ecotype \\
4 & Almalou & Ajabshir & 2000 & Dry farming, native ecotype \\
5 & Seviar & Hashtrud & 1700 & Irrigated farming, native ecotype \\
6 & Balsin & Mianeh & 1730 & Semi-Dry farming, native ecotype \\
7 & Ein-aldin & Bostanabad & 1900 & Irrigated farming, native ecotype \\
8 & Ilan-jough & Ardabil & 1800 & Irrigated farming, native ecotype \\
9 & Kordlou & Ahar & 1350 & Irrigated farming, native ecotype \\
10 & GhareYonje & Khosroshahr & 1345 & Dry farming, Improved cultivar \\
\hline
\end{tabular}

DNA isolation: Genomic DNA from 30 individual seeds of each population was extracted following Madden (2002) with mirror modification. The quantity and purity of extracted DNAs were estimated by spectrophotometry and $1 \%$ agarose gel electrophoresis. Each DNA sample was diluted to $30 \mathrm{ng}$ and kept at $-20^{\circ} \mathrm{C}$ to use for PCR amplification. DNA from bulked seeds per population was also extracted and referred to as bulked DNA sample.

RAPD amplification: Thirty eight random primers were tested and finally 10 primers were selected in this study for RAPD analysis (Table 2). PCR reactions were performed in a $25 \mu \mathrm{l}$ total volume containing $1 \mu \mathrm{l}$ of template DNA (30 ng), $4 \mathrm{pmol}$ of random primers (CinnaGen), $13 \mu \mathrm{l}$ of $1 \mathrm{X}$ PCR Master Kit (CinnaGen PCR Master Kit, Cat. No. PR8250C) and $10 \mu \mathrm{l}$ of double distilled $\mathrm{H}_{2} \mathrm{O}$. Amplifications were carried out in a Thermal cycler (Primus 96), programmed for an initial denaturation step at $94^{\circ} \mathrm{C}$ for 5 min followed by 40 cycles of $1 \mathrm{~min}$ at $93^{\circ} \mathrm{C}, 1 \mathrm{~min}$ at $40^{\circ} \mathrm{C}, 90 \mathrm{~s}$ at $72^{\circ} \mathrm{C}$ and a final extension cycle of $5 \mathrm{~min}$ at $72^{\circ} \mathrm{C}$. RAPD products were separated by electrophoresis on $1.5 \%$ agarose gels, stained with ethidium bromide, visualized with UV light and then photographed. A 1Kb DNA Ladder (Fermentas) was also loaded to estimate the size of RAPD fragments. 
Data analysis: The presence or absence of bands visualized on the gel were scored as 1 (presence) or 0 (absence) for each locus separately. The percentage of polymorphic bands per primer was defined and then within population polymorphism, genetic diversity based on Nei's gene diversity (Nei, 1973) and Shannon's Information index (Lewontin, 1972) and the genetic distances among populations (Nei, 1972) were measured by POPGEN ver 1.32 (Yeh et al., 1999) software. A matrix of pairwise genetic distances was employed to cluster the populations and UPGMA dendrogram was drawn using the sequential agglomerative hierarchical nested (SAHN; Sneath and Sokal, 1973) clustering method as available in NTSYS-pc 2.02 (Rohlf, 1998). Cophenetic correlation was measured with NTYSYS to test the association between input and output of the distance matrix (Mantel, 1967).

Table 2. Properties of arbitrary oligonucleotide primers used for RAPD analysis.

\begin{tabular}{llcccc}
\hline & & \multicolumn{2}{c}{ Individual analysis } & \multicolumn{2}{c}{ Bulk analysis } \\
\cline { 3 - 6 } Primers & Sequence (5'-3') & $\begin{array}{c}\text { Number of } \\
\text { polymorphic } \\
\text { bands }\end{array}$ & $\begin{array}{c}\text { \% of } \\
\text { polymorphic } \\
\text { bands }\end{array}$ & $\begin{array}{c}\text { Number of } \\
\text { polymorphic } \\
\text { bands }\end{array}$ & $\begin{array}{c}\text { \% of polymorphic } \\
\text { bands }\end{array}$ \\
\hline OPJ $_{4}$ & CCGAACACGG & 19 & 100.00 & 10 & 83.33 \\
$\mathrm{~B}_{1}$ & GGTTCGCTCC & 18 & 100.00 & 3 & 25.00 \\
$\mathrm{~B}_{6}$ & TGCTCTGCCC & 12 & 100.00 & 7 & 63.63 \\
$\mathrm{~B}_{7}$ & GGTGACGCAG & 12 & 92.31 & 2 & 16.67 \\
$\mathrm{~B}_{8}$ & GTCCACACGG & 11 & 91.67 & 3 & 42.86 \\
$\mathrm{OPJ}_{13}$ & CCACACTACC & 20 & 86.96 & 5 & 41.67 \\
$\mathrm{~B}_{10}$ & CTGCTGGGAC & 16 & 88.89 & 4 & 28.57 \\
$\mathrm{OPA}_{1}$ & CAGGCCCTTC & 20 & 83.33 & 12 & 80.00 \\
$\mathrm{OPJ}_{19}$ & GGACACCACT & 15 & 93.75 & 3 & 30.00 \\
OPJ $_{20}$ & AAGCGGCCTC & 13 & 86.67 & 0 & 00.00 \\
Mean & & 15.6 & 92.36 & 46 & 41.17 \\
\hline
\end{tabular}

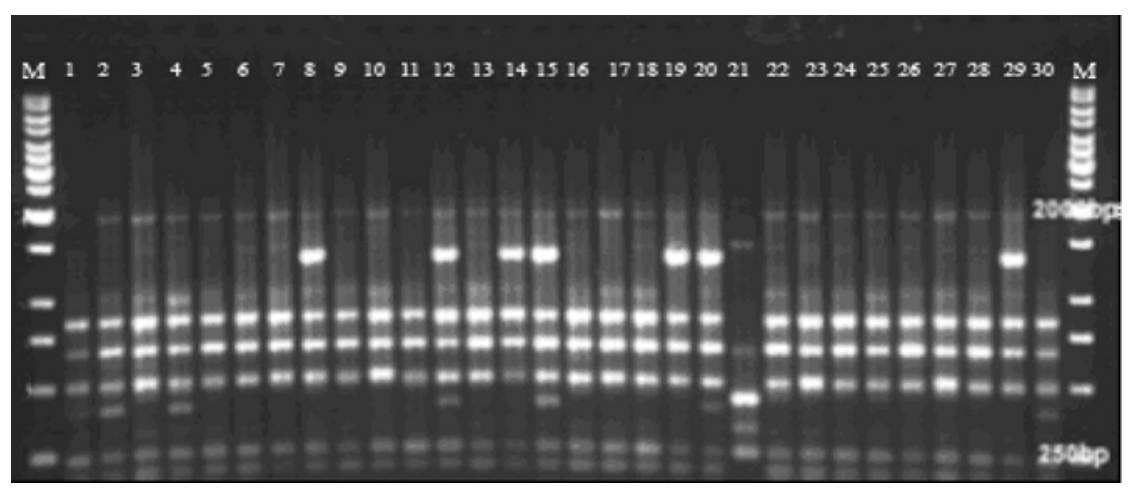

Fig. 2. RAPD fragments for Bostanabad population using the primer $\mathrm{B}_{6}$ in individual analysis. M. Molecular size marker (1 Kb). 1-30. Individuals number. 
Analysis of molecular variance (AMOVA) was performed to estimate hierarchical variance components (among individuals within populations, among populations and among groups). AMOVA was carried out via ARLEQUIN 3 (Excoffier et al., 2005). To show a graphical representation of the relationships among populations, principal coordinates analysis (PCoA) was performed using NTSYS-pc, version 2.02. Genetic distances among populations for bulk analysis were estimated and cluster analysis and principal coordinates analyses were performed.

\section{Results}

Among 38 random primers tested in this study, 10 primers generated reproducible bands (Table 2). Fig. 2 and Fig. 3 show RAPD fragments in individual plant study and bulk analysis, respectively.

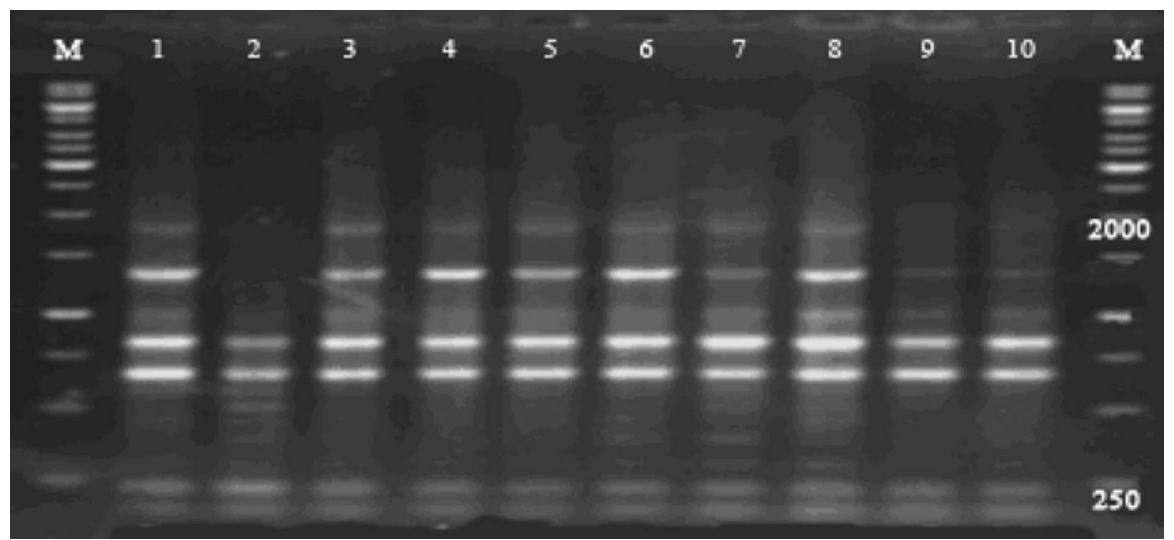

Fig. 3. RAPD fragments for 10 populations using the primer $\mathrm{B}_{6}$ in bulk analysis. M. Molecular size marker (1 Kb). 1-10. Populations number.

Table 3. Within-population polymorphism and gene diversity $\left({ }^{1}\right.$ Nei'gene diversity, ${ }^{2}$ Shannons information index).

\begin{tabular}{ccccc}
\hline $\begin{array}{c}\text { Population } \\
\text { number }\end{array}$ & $\begin{array}{c}\text { Number of } \\
\text { polymorphic bands }\end{array}$ & $\begin{array}{c}\text { \% of polymorphic } \\
\text { bands }\end{array}$ & $\mathrm{h}^{1}$ & $\mathrm{I}^{2}$ \\
\hline 1 & 112 & 65.88 & 0.1977 & 0.3058 \\
2 & 98 & 57.65 & 0.1715 & 0.2671 \\
3 & 107 & 62.94 & 0.1891 & 0.2925 \\
4 & 119 & 70.00 & 0.1975 & 0.3091 \\
5 & 116 & 68.24 & 0.1991 & 0.3090 \\
6 & 110 & 64.71 & 0.1801 & 0.2819 \\
7 & 107 & 62.94 & 0.1753 & 0.2748 \\
8 & 113 & 66.47 & 0.1843 & 0.2874 \\
9 & 118 & 69.41 & 0.2114 & 0.3238 \\
10 & 105 & 61.76 & 0.1864 & 0.2876 \\
Mean & 110.5 & 65 & 0.1892 & 0.2939 \\
\hline
\end{tabular}


Individual analysis:

A total of 156 polymorphic bands ranging from 250 to $2500 \mathrm{bp}$ were identified. Three primers $\left(\mathrm{B}_{1}, \mathrm{~B}_{6}\right.$ and $\left.\mathrm{OPJ}_{4}\right)$ produced $100 \%$ polymorphic bands. Minimum percentage of polymorphic bands was observed by primer $\mathrm{OPA}_{1}$ (Table 2). The percentage of polymorphic bands within populations differed from $57.65 \%$ for population 2 to $70 \%$ for population 4 (Table 3). Additionally, the populations 9 and 2 showed the maximum and minimum genetic diversity (Table $3)$, respectively. Total genetic diversity $\left(H_{\mathrm{T}}\right)$ and within population genetic diversity $(H \mathrm{~s})$ were calculated as 0.2349 and 0.1892 , respectively and the degree of genetic differentiation among populations $\left(G_{\mathrm{ST}}\right)$ was estimated as 0.1944. These results indicated that diversity within populations was greater than that among populations. Genetic distances among pairs of populations ranged from 0.025 between populations 7 and 8 to 0.1103 between populations 2 and 10. The average distance among populations was 0.0631 . In total, genetic distances among populations were low (Table 4).

Table 4. Nei's genetic distances between populations for individual analysis (lower diagonal) and bulk analysis (upper diagonal). Mean for upper diagonal: 0.1169; Mean for lower diagonal: 0.0631

\begin{tabular}{ccccccccccc}
\hline Population & 1 & 2 & 3 & 4 & 5 & 6 & 7 & 8 & 9 & 10 \\
\hline 1 & & 0.0919 & 0.0543 & 0.0857 & 0.1149 & 0.0703 & 0.0870 & 0.1243 & 0.1363 & 0.0869 \\
2 & 0.0341 & & 0.1150 & 0.0667 & 0.1220 & 0.1542 & 0.1149 & 0.1428 & 0.1566 & 0.1264 \\
3 & 0.0391 & 0.0417 & & 0.0857 & 0.0919 & 0.0595 & 0.0869 & 0.1135 & 0.1136 & 0.0543 \\
4 & 0.0616 & 0.0859 & 0.0595 & & 0.0667 & 0.1250 & 0.1200 & 0.1477 & 0.1617 & 0.1200 \\
5 & 0.0490 & 0.0779 & 0.0652 & 0.0413 & & 0.1314 & 0.1149 & 0.1314 & 0.1253 & 0.1149 \\
6 & 0.0487 & 0.0528 & 0.0447 & 0.0575 & 0.0428 & & 0.1027 & 0.1290 & 0.1751 & 0.0919 \\
7 & 0.0358 & 0.0438 & 0.0392 & 0.0774 & 0.0620 & 0.0538 & & 0.0702 & 0.1023 & 0.0543 \\
8 & 0.0434 & 0.0701 & 0.0506 & 0.0553 & 0.0491 & 0.0530 & 0.0250 & & 0.1073 & 0.1027 \\
9 & 0.0760 & 0.0886 & 0.0830 & 0.0978 & 0.0934 & 0.0848 & 0.0792 & 0.0645 & & 0.0795 \\
10 & 0.0674 & 0.1103 & 0.0978 & 0.1050 & 0.0831 & 0.0950 & 0.0872 & 0.0663 & 0.0791 & \\
\hline
\end{tabular}

Genetic distance values were used to construct a UPGMA dendrogram and populations were divided into three groups (Fig. 4). First groups included population 10 (a breeding population) and second group included population 9. Other populations belonged to third group. Matrix correlation was estimated as 0.849 . To study relationships among populations, AMOVA was performed based on population clustering (significance tests were provided by computing 1023 permutations). Significant differences were observed among groups, among populations within groups and among individuals within populations. However, the high genetic variation (76.08\%) was attributed to differences within populations (Table 5).

AMOVA was also performed in population level to estimate diversity within and between populations $\left(F_{\mathrm{ST}}=0.186 ; \mathrm{p}=0.05\right)$. Although variation among populations was significant, the great genetic diversity (81.37\%) was observed within populations (Table 5). Fig. 5 shows the results of PCoA. On the basis of the first and second coordinates, which accounted for $29.29 \%$ and $19.29 \%$ of the total variation, respectively, populations were distributed in three groups. Populations 10 and 9 belonged to first and second groups, respectively and the other populations belonged to third group. 
Table 5. Results of analysis of molecular variance (AMOVA) in individual analysis.

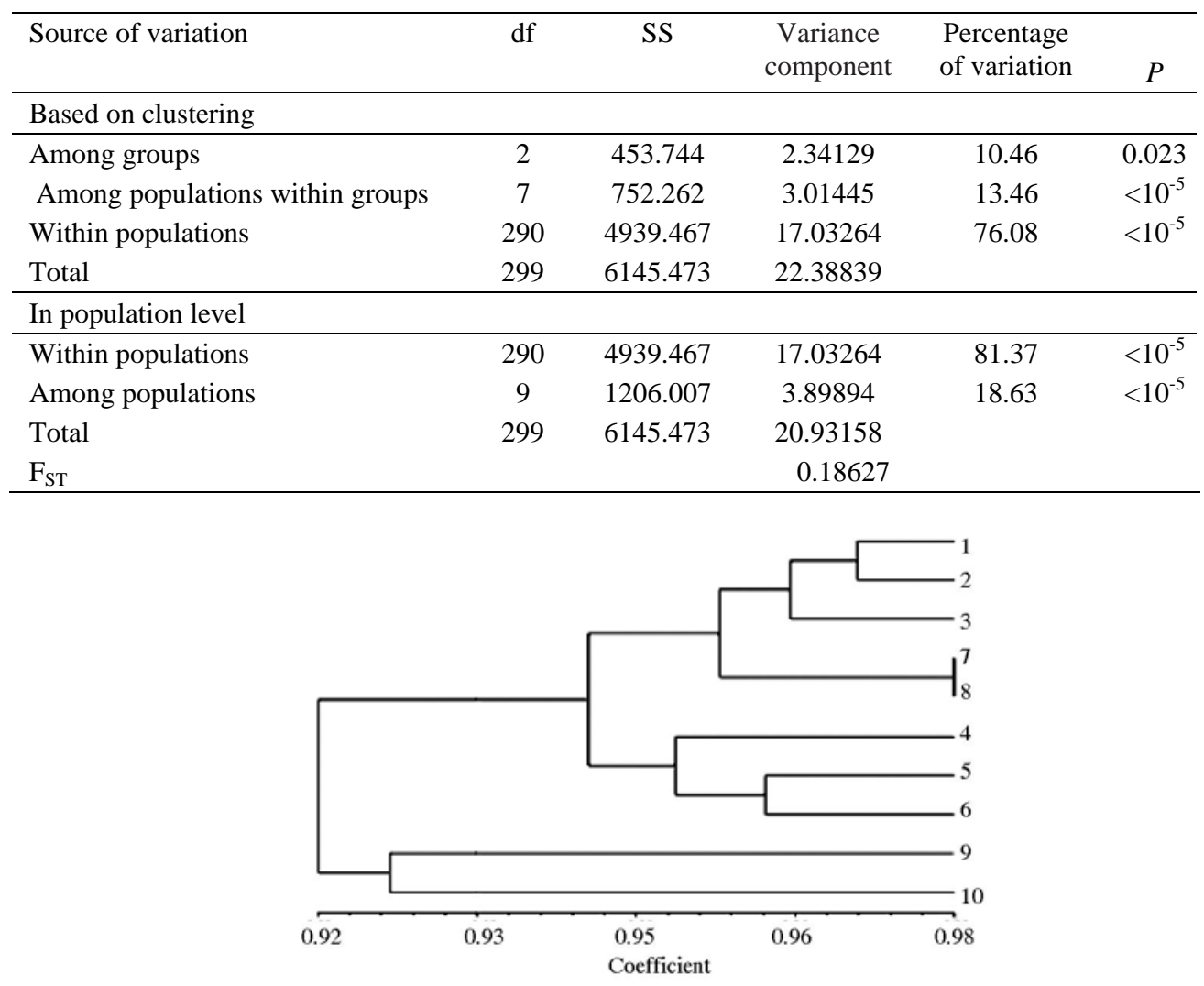

Fig. 4. UPGMA dendrogram for alfalfa populations based on Nei's genetic distances in individual analysis.

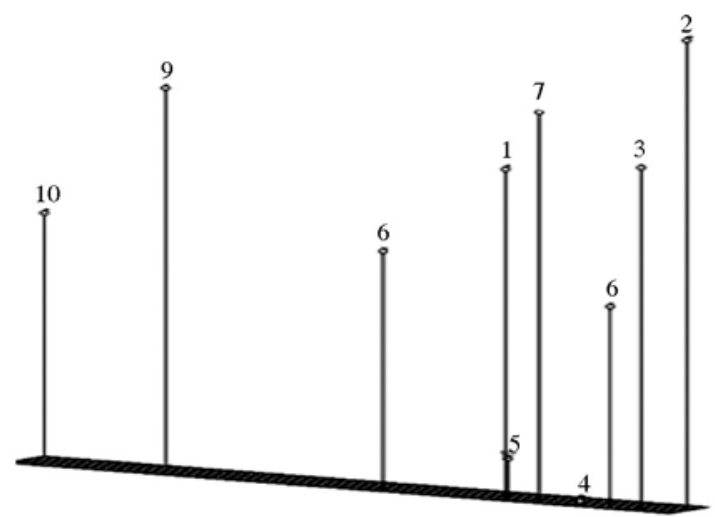

Fig. 5. Principal coordinates analysis (PCoA) for alfalfa populations based on the first and second coordinates (in individual analysis). 


\section{Bulk analysis:}

A total 46 polymorphic bands were identified in bulk analysis. Maximum and minimum percentages of polymorphic bands were observed by primers $\mathrm{OPJ}_{4}$ and $\mathrm{OPJ}_{20}$, respectively. The average percentage of polymorphic bands was 41.17 \% (Table 2). Cluster analysis based on Nei's genetic distances (Table 4) divided populations into three groups (Fig. 6). First group included populations 8 and 9, the second groups included populations 5, 4, and 2 and third groups included the others. Matrix correlation was estimated as 0.712 . PCoA was performed for bulk samples and populations were located into 3 groups (Fig. 7).

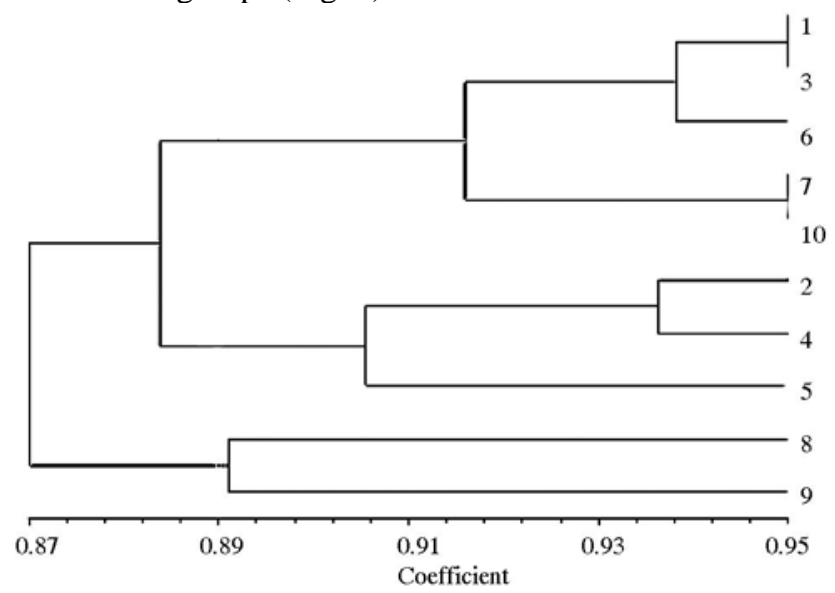

Fig. 6. UPGMA dendrogram for alfalfa populations based on Nei’s genetic distances in bulk analysis.

The first and second coordinates accounted for $29.29 \%$ and $19.29 \%$ of the total variation, respectively. In total, results of bulk analysis were different from results of individual analysis.

\section{Discussion}

In the present study we analyzed 10 alfalfa populations from diverse regions of Azarbaijan, Iran using RAPD profiles. Since reproducibility is an important factor in RAPD studies (Ulloa et al., 2003), only reproducible bands were used in present investigation.

In individual analysis, ten primers produced 156 polymorphic bands with an average 15 polymorphic bands per primer. This can be favorably compared with the number of bands used by Tucak et al. (2008) to estimate genetic diversity in alfalfa populations and is higher than the number of bands used by Dehghan-Shoar (1997) and Mengoni et al. (2000) to study alfalfa populations. In terms of population genetic parameters, total gene diversity $\left(H_{\mathrm{T}}\right)$ observed in this study was high. It was in consistent with previous studies. Mengoni et al. (2000) suggested that high level of genetic diversity is observed in alfalfa populations. Moreover, Falahati-Anbaran et al. (2007) studied population genetic structure in alfalfa from various regions contiguous to the centers of origin of the species. They proposed that since northwestern of Iran is the primary centre of diversity for alfalfa, so high level of genetic diversity exists within and among Iranian 
alfalfa populations such as populations employed in this work. However, the within population diversity (based on Nei's gene diversity) was high for each population, as found in previous studies (Flajoulot et al., 2005; Falahati-Anbaran et al., 2007; Tucak et al., 2008). Gherardi et al. (1998) also suggested that the within population diversity is higher than diversity among populations. It can be explained by the outcrossing and tetraploid nature of alfalfa that results in highly heterogeneous and heterozygous populations (Kidwell et al., 1994).

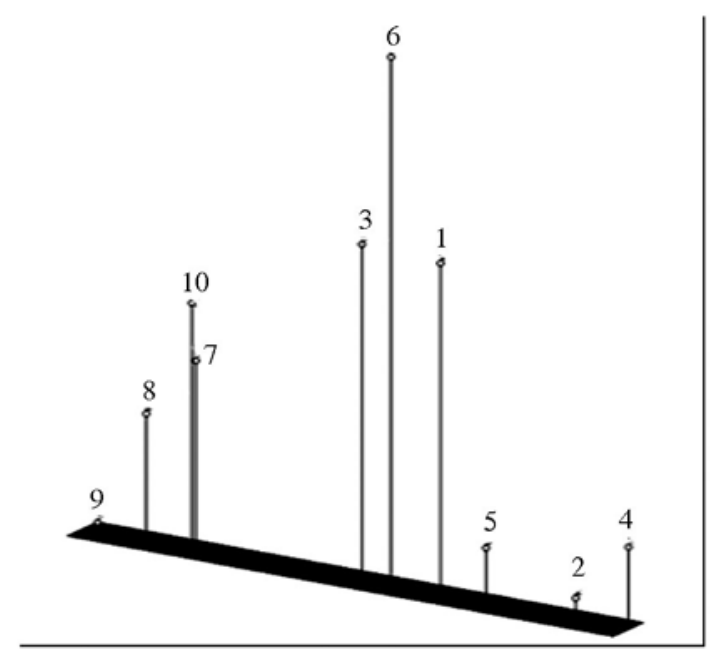

Fig. 7. Principal coordinates analysis (PCoA) for alfalfa populations based on the first and second coordinates in bulk analysis.

Results of analysis of molecular variance suggested that the largest proportion of genetic variation was attributed to variation among individuals within populations (81.37\%). These results were in agreement with previous studies (Falahati-Anbaran et al., 2007; Tucak et al., 2008). Low genetic distances were detected between populations possibly due to small geographical distances existed between them. In spite of it, cluster analysis could group populations and AMOVA based on population grouping showed a significant distance between groups. The largest genetic distance was observed between populations number 10 (Ghareh Yonjeh) and number 2 (Zonorag). Separation of Ghareh Yonjeh which is a breeding population from the other populations indicates the sufficiency of this method to study relationship in alfalfa populations. Falahati-Anbaran et al. (2007) could also separate Ghareh Yonjeh from other Iranian alfalfa populations. Population number 9 was clustered into a distinct group. Morphological studies indicated differences among this population and other populations. Thereupon, separation of it from other populations of Azarbaijan can be related to morphological differences. Other populations grouped together in one cluster and formed a different branch in the dendrogram. Distribution of these populations on distinct branch was in agreement with geographical patterns of them. 
Cluster analysis in bulk method could not separate Ghareh Yonjeh from other populations and genetic differentiation of populations was not in agreement with geographical or morphological patterns. Such differences among results obtained from bulk analysis and individual analysis were observed in previous studies (Mengoni et al., 2000; Pupilli et al., 2000). Negri et al. (1995) and Pupilli et al. (2000) reported that bulk procedure reduces within population diversity when frequency of polymorphic fragments is low. Some DNA sequences are found in a few individuals and produce rare fragments in individual analysis. Since these sequences compose a low concentration of template DNA in bulked sample, they can not efficiently be amplified. So rare fragments observed in individual analysis are absent in bulk analysis (Yu and Pauls, 1993) as observed in our study. Kidwell et al. (1994) also proposed that bulk method underestimates the level of genetic diversity in both within and between populations and results of differentiation among populations in bulk analysis are not in agreement with individual analysis. This was true especially in our study with 30 individuals per bulk sample. Since using of greater number of individuals in bulk samples reduces the probability of detecting rare fragments that may be diagnostic of a population, so differentiation between populations was not carried out precisely (Kidwell et al., 1994).

The high level of genetic diversity observed within populations in our study, particularly population 4, 5 and 9, indicates each population as a genetic source for selection of suitable genotypes to employ them in breeding programs and improve alfalfa cultivars with high level of heterosis. Furthermore results of cluster analysis indicated that GhareYonje and population number 9, are different from other populations. Thus each of them can be used as parents in breeding programs. Bulk method offers a rapid analysis of RAPD patterns in genetic study of alfalfa population. However, comparison of bulk analysis with individual analysis showed that it is better to use individual analysis in detection of relationships among alfalfa populations and estimation of genetic diversity especially within populations.

Finally, RAPD analysis was demonstrated as a suitable method to study genetic diversity and relationships among alfalfa populations. However it is advised to accompany results of RAPD procedure with other molecular methods and morphological studies.

\section{Acknowledgments}

This research was performed in the Agricultural Biotechnology Research Institute of Iran (ABRII), for Northwest and West of Iran, Tabriz-Ian. We thank Ms Nahid Hosseinzadeh for her editorial assistance.

\section{References}

Arzani, A. and Samei, K. 2004. Assessment of genetic diversity among Persian clover cultivars as revealed by RAPD markers. In: Vollmann, J., Grausgruber, H. and Ruckenbauer, P. (ed.), Genetic variation for plant breeding. EUCARPIA and BOKU, University of Natural Resources and Applied Life Sciences, Vienna, pp. 85-88. 
Dehghan-Shoar, M., Hampton, J.G. and Gardiner, S.E. 1997. Genetic analysis among and within populations forming ecotypes and cultivars of lucerne, Medicago sativa (Leguminosae), using RAPD fragments. Pl. Syst. Evol. 208: 107-119.

Excoffier, L., Laval, G. and Schneider, S. 2005. Arlequin (version 3.0): An integrated software package for population genetics data analysis. Evol. Bioinf. Online 1: 47-50.

Falahati-Anbaran, M., Habashi, A.A., Esfahany, M., Mohammadi, S.A. and Gharayazie, B. 2007. Population genetic structure based on SSR markers in alfalfa (Medicago sativa L.) from various regions contiguous to the centres of origin of the species. J. Genet. 86: 59-63.

Flajoulot, S., Ronfort, J. Baudouin, P., Barre, P., Huguet, T., Huyghe, C. and Julier, B. 2005. Genetic diversity among alfalfa (Medicago sativa) cultivars coming from a breeding program, using SSR markers. Theor. Appl. Genet. 111: 1420-1429.

Gherardi, M., Mangin, B., Goffinet, B., Bonnet, D. and Huguet, T. 1998. A method to measure genetic distance between allogamous populations of alfalfa (Medicago sativa) using RAPD molecular. Theor. Appl. Genet. 96: 406-412.

Hanson, A.A., Barnes, D.K. and Hill, R.R. 1988. Alfalfa and alfalfa improvement. Madison, Wisconsin, USA.

Jenczewski, E., Prosperi, J.M. and Ronfort, J. 1999. Differentiation between nature and cultivated population of Medicago sativa (Leguminosae) from Spain. Analysis with random amplified polymorphic DNA (RAPD) markers and comparison with allozymes. Mol. Ecol. 8: 1317-1330.

Kidwell, K.K., Austin, D.F. and Osborn, T.C. 1994. RFLP evaluation of nine Medicago accessions representing the original germplasm sources of North American alfalfa cultivars. Crop Sci. 34: 230-236.

Lewontin, R.C. 1972. The apportionment of human diversity. Evol. Biol. 6: 38-398.

Madden, D. 2002. Investigating plant DNA. Technical guide. NCBE. The University of Reading, United Kingdom.

Mantel, N.A. 1967. The detection of disease clustering and generalized regression approach. Cancer Res. 27: 209-220.

Mengoni, A., Gori, A. and Bazzicalupo, M. 2000. Use of RAPD and microsatellite (SSR) variation to assess genetic relationships among populations of tetraploid alfalfa, Medicago sativa. Plant Breed. 119: 311317.

Michelmore, R.W., Paran, I. and Kesseli, R.V. 1991. Identification of markers linked to disease-resistance genes by bulked segregate analysis: A rapid method to detection markers in specific genomic regions by using segregating populations. Proc. Natl. Acad. Sci. USA. 88: 9828-9832.

Negri, V., Barcaccia, G., Russi, L., Tavoletti, S., Pellicoro, A. and Falcinelli, M. 1995. RAPD fingerprinting as a tool for characterizing the genetic background of Lucerne (Medicago sativa L.) landraces. Universita degli Studi di Ancona, Italy.

Nei, M. 1972. Genetic distance between populations. Am. Nat. 106: 283-292.

Nei, M. 1973. Analysis of gene diversity in subdivided population. Proc. Natl. Acad. Sci. USA. 70: 33213323.

Pupilli, F., Labombarda, P., Scott, C. and Arcioni, S. 2000. RFLP analysis allows for the identification of alfalfa ecotypes. Plant Breed. 119: 271-276.

Rahman, M.O. 2006. Evaluation of RAPD markers for taxonomic relationships in some aquatic species of Utricularia L. (Lentibulariaceae). Bangladesh J. Plant Taxon. 13(2): 73-82.

Rohlf, F.J. 1998. NTSYS-pc, Numerical taxonomy and multivariate analysis system, version 2.02. Exeter Software, New York, USA. 
Rowe, D.E. and Hill, R.R. 1999. Breeding theory and the development of alfalfa. The Alfalfa Genome. (www.naaic.org/TAG/TAGpapers/RoweAbs.html).

Sneath, P.H.A. and Sokal, R.R. 1973. Numerical Taxonomy. Freeman, San Francisco.

Tucak, M., Popovic, S., Cupic, T., Bolaric, S. and Kozumplic, V. 2008. Genetic diversity of alfalfa (Medicago spp.) estimated by molecular markers and morphological characters. Period. Biol. 110(3): 243-249.

Ulloa, O., Ortega, F. and Campos, H. 2003. Analysis of genetic diversity in red clover (Trifolium pratense L.) breeding populations as revealed by RAPD genetic markers. Genome 46(4): 529-535.

Vandemark, G.J., Ariss, J.J., Bauchan, G.A., Larsen, C.R., Hughes, J.T. 2006. Estimating genetic relationships among historical sources of alfalfa germplasm and selected cultivars with sequence related amplified polymorphisms. Euphytica 152: 9-16.

Veronesi, F., Brummer, E.C. and Huyghe, C. 2010. Alfalfa. In: Boller, B., Posselt, U.K. and Veronesi, F. (ed.), Fodder Crops and Amenity Grasses. Series: Handbook of Plant Breeding, Springer, New York, USA. 5: 395-437.

Volenec, J.J., Cunningham, S.M., Haagenson, D.M., Berg, W.K., Joern, B.C. and Wiersma, D.W. 2002. Physiological genetics of alfalfa improvement: past failures, future prospects. Field Crop Res. 75: 97110.

Williams, J.G.K., Kubelik, A.R., Livak, K.J., Rafalski, J.A. and Tingey, S.V. 1990. DNA polymorphisms amplified by arbitrary primers are useful as genetic markers. Nucleic Acids Res. 18: 6531-6535.

Yeh, F.C., Yang, R.C., Boyle, T.B.J., Ye, Z.H. and Mao, J.X. 1999. POPGENE (the user-friendly shareware for population genetic analysis), version 1.32. Molecular Biology and Biotechnology Centre, University of Alberta, Edmonton, Canada.

Yu, K. and Pauls, K.P. 1993. Rapid estimation of genetic relatedness among heterogeneous populations of alfalfa by random amplification of bulked genomic DNA samples. Theor. Appl. Genet. 86: 788-794.

(Manuscript received on 21 August 2010; revised on 2 December 2011) 